ECCOMAS

Proceedia
COMPDYN 2021

$8^{\text {th }}$ ECCOMAS Thematic Conference on

Computational Methods in Structural Dynamics and Earthquake Engineering

M. Papadrakakis, M. Fragiadakis (eds.)

\title{
EFFECT OF LEAD RUBBER BEARING (LRB) MODELING TECHNIQUE ON THE SEISMIC RESPONSE OF BASE-ISOLATED BRIDGES
}

\author{
Vahid Aghaeidoost ${ }^{1 *}$, AHM Muntasir Billah ${ }^{2}$ \\ ${ }^{1 *}$ Lakehead University \\ 955 Oliver Road, Thunder Bay, ON, P7B5E1, Canada \\ e-mail: vaghaei@lakeheadu.ca \\ ${ }^{2}$ Lakehead University \\ 955 Oliver Road, Thunder Bay, ON, P7B5E1, Canada \\ muntasir.billah@lakeheadu.ca
}

\begin{abstract}
Seismic isolation bearings are one of the most widely used seismic protection systems for bridges. Taking advantage of improved energy dissipation and flexibility, Lead Rubber Bearings (LRB) have emerged as a popular solution for seismic protection of bridges. Over the last few decades, LRBs have been studied significantly both experimentally and numerically, resulting in different numerical modeling approaches of LRB. Since the seismic response of a base-isolated bridge largely depends on the modeling technique adopted for the bearing element, it is essential to identify an appropriate modeling scheme for LRBs. The objective of this study is to investigate the seismic response sensitivity of an isolated bridge when different LRB modeling techniques are adopted. In this study, a three-span curved steel girder bridge isolated with LRB is considered as the reference bridge that was tested in a shake table at the University of Nevada, Reno. The validated numerical model of the reference bridge is first developed using OpenSees. Three different LRB modeling techniques available in OpenSees are used to model the isolation bearings. Using the ElastomericX, LeadRubberX, and KikuchiAikenLRB modeling techniques, the seismic response of the bridge is compared against the experimental results. The performance of the isolated bridge is evaluated in terms of isolator force-deformation relationship and fragility curves. The analysis results show that LRB modeling approach has a noteworthy impact on the seismic response of base-isolated bridge and requires careful selection of modeling parameters.
\end{abstract}

Keywords: Lead rubber bearing, Seismic response, Curved Bridge, Numerical modeling, Dynamic analysis. 


\section{INTRODUCTION}

Bridges are one of the vital infrastructures of any country's transportation network. Bridge damage due to a strong earthquake leads to the cessation of the function of these vital infrastructures at critical times, which are needed to provide emergency services or help evacuating a damaged area. The use of seismic isolators is one of the effective methods to improve the seismic performance of bridges. With seismic isolators, ductility increases, and forces applied to the bridge structure due to earthquakes decrease. The behavior and performance of seismic isolation systems are highly nonlinear and more complex than other structural elements (such as girders, cap beams, columns) and can be affected by several factors.

Behavioral characteristics of nonlinear seismic isolators are a function of the dynamic responses of seismic isolators during an earthquake, and this poses severe challenges for modeling the response of these seismic isolators. To overcome these challenges, several main aspects of isolation bearing modeling, are: (a) bidirectional motion coupling in the horizontal plane, (b) the relationship of vertical and horizontal motion of the seismic isolator, (c) cavitation behavior and post-cavity seismic isolator in tension, (d) decrease in tensile cyclic loading resistance during cavitation behavior, (e) changes in critical buckling load capacity due to lateral displacement [1].

The flexibility of seismic isolators increases the fundamental period of base-isolated bridges and reduces the seismic forces applied to them. Although this reduction may be associated with large horizontal displacements of the seismic isolators, lateral flexibility plus horizontal displacements result in a significant reduction in the critical buckling load capacity of the seismic isolator [2-5].

An experimental study by Buckle et al. [6] on a set of seismic isolators showed that the critical loading capacity decreases with an increasing horizontal displacement or shear strain, and the horizontal stiffness decreases with increasing axial load and horizontal displacement [2]. Recent studies and experience of past earthquakes have shown that the impact of considering the vertical component of ground motions is significant for the analysis and design of structures.

Shekar et al. [7] investigated the effect of dampers and design standards on the response of highway bridges. They developed a three-dimensional model for this purpose. A significant vulnerability of the non-seismic bridge designed with a bearing could be observed because of the bridge pier's non-ductile failure. With the modern seismic design, the vulnerability of the bridge was significantly reduced.

The objective of this study is to investigate the seismic response sensitivity of an isolated bridge when different LRB modeling techniques are adopted. In this study, a three-span curved steel girder bridge isolated with LRB is considered as the reference bridge that was tested in a shake table at the University of Nevada, Reno [8]. The distinguishing feature of this study is that conventional simplifications are not used in seismic isolator modeling techniques, and instead, the main aspects of modeling and the factors affecting the behavior of isolators are fully included in the modeling. For this purpose, Lead Rubber Bearing (LRB) is studied using different modeling techniques available in OpenSees, and by performing Incremental Dynamic Analysis (IDA) and fragility analysis, different bridge responses under nearfault ground motions are studied. 


\section{MODEL OF BRIDGE}

\subsection{Description}

The bridge considered in this study was designed and experimentally tested at the University of Nevada, Reno [8]. The bridge is a three-span composite steel I-girder bridge. Fig.1 indicates the plan of the bridge model and shows the location of abutments and piers. The design and geometric details of the scaled bridge can be found in [8]. This bridge superstructure has three composite steel I-girders with an $83 \mathrm{~mm}$ concrete deck. The lengths of the spans are $12.8,18.6$, and $12.8 \mathrm{~m}$, respectively (total length 44.2 meters), and the centerline radius is $24.4 \mathrm{~m}$. The width of the deck is $3.66 \mathrm{~m}$ and the distance between the girders is $1.37 \mathrm{~m}$. The height of the columns and their diameters are 2.44 and $0.61 \mathrm{~m}$, respectively.

Fig. 2 shows the detailed numerical model of the bridge used in this study. The piers are mono-column with $1 \%$ longitudinal and transverse steel rebar ratios. The concrete compressive strength is $44 \mathrm{MPa}$ and the steel reinforcement is A706 grade with a yield strength of 490 $\mathrm{MPa}$. The total bridge model weight is $1486 \mathrm{kN}$ that is spread along with the longitudinal nodes of the deck.

In the numerical simulation with OpenSees, the confined and unconfined concrete behavior is considered and calculated according to the Chang and Manders [28] model (Concrete07). The reinforcing steel properties are simulated using steel02 model. The superstructure elements are assumed as elastic element and the piers and LRB are considered as nonlinear elements. The effect of soil-structure interaction is ignored in this study.

\subsection{Lead rubber bearing systems}

Three modeling techniques are used for modeling LRB as a seismic base isolation system. The LRB characteristics such as, shear modulus, modulus of elasticity, and characteristic strength are $0.41 \mathrm{MPa}, 1.24 \mathrm{MPa}$, and 6.27 (Abutment), 9.03 (Pier) kN, respectively. More details about designing the LRB can be found in [8]. Three techniques are used for modeling LRB in Opensees: (a) KikuchiAikenLRB material with the zero-length element, (b) ElastomericX element, and (c) LeadRubberX element. The fundamental period of the base-isolated bridge with three LRB modeling techniques is found to be $0.66,0.68$, and $0.68 \mathrm{sec}$, respectively.

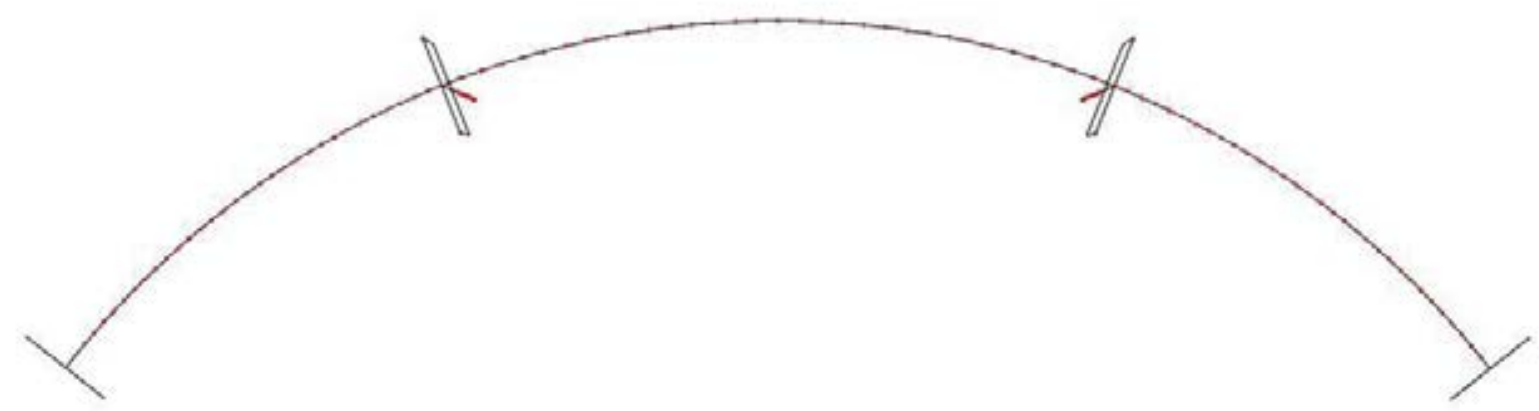

Figure 1: Bridge Plan. 


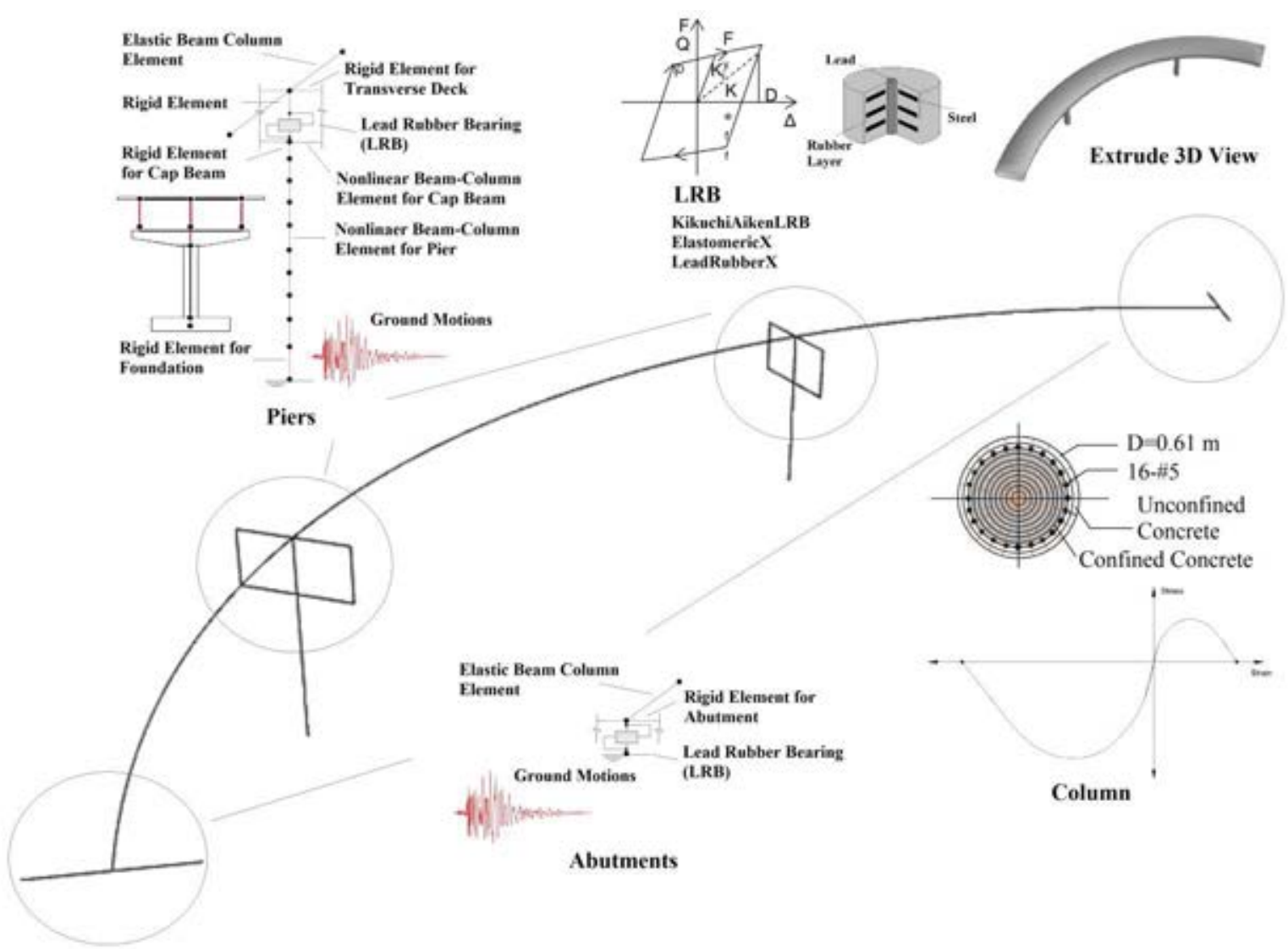

Figure 2: Numerical model of the bridge details.

\section{MODEL VERIFICATION}

The $2 / 5^{\text {th }}$ scale bridge model was tested in shake table at the University of Nevada, Reno under the Sylmar station motion from the 1940 Imperial Valley earthquake as the Design Earthquake (DE). The tests were conducted at increments of $10 \%$ to $300 \%$ of the DE. To validate the numerical modeling approach adopted in this study, the test results obtained from the $100 \%$ DE is considered in this study. The hysteretic response of the LRB obtained from the shake table results are verified with the KikuchiAikenLRB, ElastomericX, and LeadRubberX modeling techniques. Fig. 3 shows the hysteresis curves of the LRB at the pier location. According to this figure, the shape of the hysteresis curves is similar to the experimental hysteresis curve. In Table 1, the experimental responses in terms of the maximum shear force, displacement along the $\mathrm{x}$-direction, both in positive and negative, and the energy dissipation are compared with the three mentioned techniques. For maximum shear force, all three models over predicted the force in the positive direction while under predicted in the negative direction. Similar observation can be made from the comparison of maximum bearing deformation. In terms of energy dissipation, the difference between the experimental and numerical results using KikuchiAikenLRB, ElastomericX, and LeadRubberX modeling techniques are $13 \%, 14 \%$, and $9 \%$, respectively. 

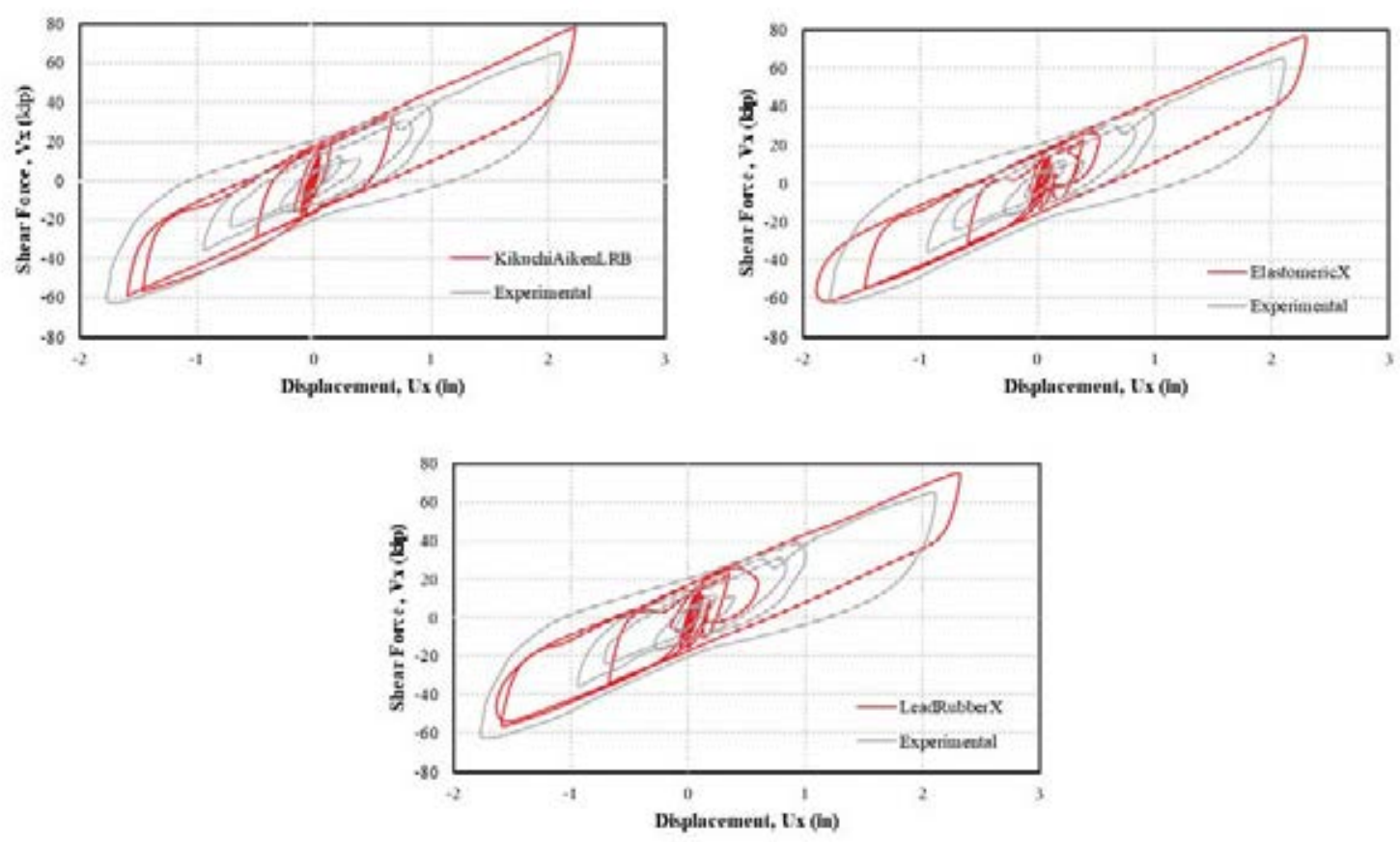

Figure 3: Hysteresis curve verification for LRB modeling techniques (a) KikuchiAikenLRB, (b) ElastomericX, and (c) LeadRubberX with Experimental result.

\begin{tabular}{|c|c|c|c|c|}
\hline Parameters & Experimental & KikuchiAikenLRB & ElastomericX & LeadRubberX \\
\hline Max. Shear force & +64.89 & 78.80 & 76.86 & 75.24 \\
\hline (kip) & $-\quad-62.67$ & -59.33 & -61.75 & -56.41 \\
\hline Max. Displacement & +2.10 & 2.23 & 2.29 & 2.32 \\
\hline & $-\quad-1.78$ & -1.59 & -1.89 & -1.63 \\
\hline $\begin{array}{l}\text { Energy Dissipation } \\
\left(\mathrm{kip} . \mathrm{in}^{2} / \mathrm{s}^{2}\right)\end{array}$ & 243.18 & 212.36 & 210.12 & 222.04 \\
\hline
\end{tabular}

Table 1: Verification of LRB techniques with Experimental results.

\section{GROUND MOTION SELECTION}

After validating the numerical models, the sensitivity of the three modeling techniques is compared by conducting seismic fragility analysis of the isolated bridges. To develop fragility curves, appropriate ground motions according to FEMA P695 [29] are selected. Table 2 shows the characteristics of the selected 14 non pulse near-field ground motions for increment dynamic analysis (IDA). The ground motions are extracted from the Pacific Earthquake Engineering Research (PEER) earthquake database [9]. The recorded primary orientations (provided by PEER (NGA)) of selected ground motions are rotated to strike-parallel and strikenormal orientations. Individual response spectrum variation of selected records and mean and mean \pm standard deviation are illustrated in Figure 4. 


\begin{tabular}{|c|c|c|c|c|c|c|}
\hline \multirow{3}{*}{$\begin{array}{l}\text { ID } \\
\text { No. }\end{array}$} & \multicolumn{3}{|c|}{ Earthquake } & \multicolumn{2}{|l|}{ Recording Station } & \multirow{3}{*}{$\begin{array}{c}\mathrm{R}_{\text {rup }} \\
(\mathrm{km})\end{array}$} \\
\hline & $\bar{M}$ & Year & Name & Name & $\begin{array}{l}\text { PGA } \\
\text { (g) }\end{array}$ & \\
\hline & \multicolumn{5}{|c|}{ No Pulse Records Subset } & \\
\hline 1 & 6.8 & 1976 & Gazli, USSR & Karakyr & 0.864 & 5.460 \\
\hline 2 & 6.5 & 1979 & Imperial Valley-06 & Bonds Corner & 0.777 & 2.660 \\
\hline 3 & 6.5 & 1979 & Imperial Valley-06 & Chihuahua & 0.270 & 7.290 \\
\hline 4 & 6.8 & 1985 & Nahanni, Canada & Site 1 & 1.201 & 9.600 \\
\hline 5 & 6.8 & 1985 & Nahanni, Canada & Site 2 & 0.519 & 4.930 \\
\hline 6 & 6.9 & 1989 & Loma Prieta & BRAN & 0.502 & 10.72 \\
\hline 7 & 6.9 & 1989 & Loma Prieta & Corralitos & 0.645 & 3.850 \\
\hline 8 & 7.0 & 1992 & Cape Mendocino & Cape Mendocino & 1.494 & 6.960 \\
\hline 9 & 6.7 & 1994 & Northridge-01 & LA - Sepulveda VA & 0.932 & 8.440 \\
\hline 10 & 6.7 & 1994 & Northridge-01 & Northridge - Saticoy & 0.459 & 12.09 \\
\hline 11 & 7.5 & 1999 & Kocaeli, Turkey & Yarimca & 0.322 & 4.830 \\
\hline 12 & 7.6 & 1999 & Chi-Chi, Taiwan & TCU067 & 0.499 & 0.620 \\
\hline 13 & 7.6 & 1999 & Chi-Chi, Taiwan & TCU084 & 1.009 & 11.48 \\
\hline 14 & 7.9 & 2002 & Denali, Alaska & TAPS Pump Sta \#10 & 0.333 & 2.740 \\
\hline
\end{tabular}

Table 2: Selected non-pulse ground motions according to FEMA P695.

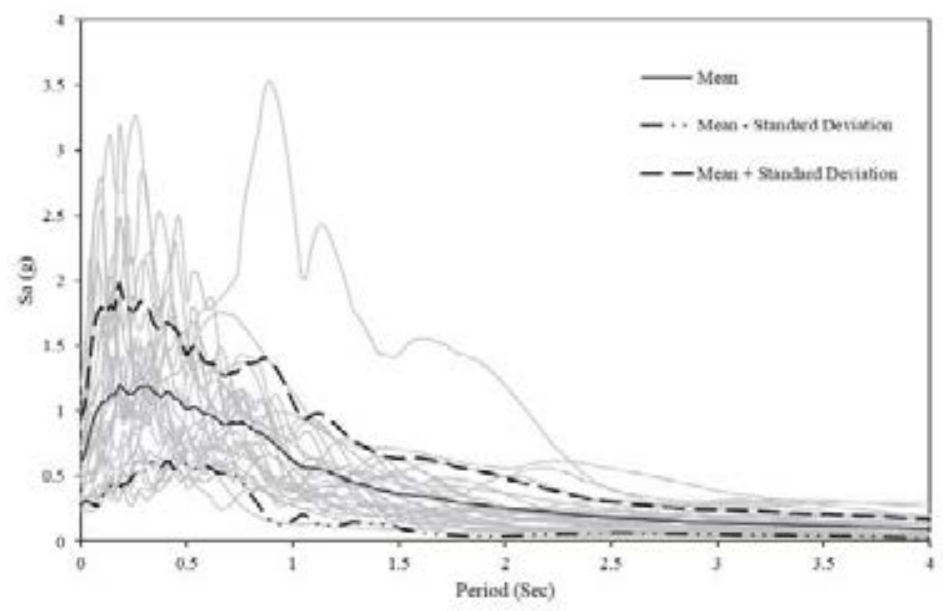

Figure 4: Response spectra of selected non-pulse ground motions, also, to mean and mean \pm standard deviation.

\section{ENGINEERING DEMAND PARAMETES (EDPs)}

Bridge piers and base-isolation systems of the bridge typically govern the response of the bridge system over other elements. Diverse sorts of EDPs such as pier displacement, bridge pier ductility, isolation bearing displacement, bearing shear strain (\%), etc., have been used by different researchers to quantify the damage in bridge pier and isolation bearing. Shear strain $(\%)$ or bearing displacement is usually used to define the damage states $[10,11]$ for the baseisolation system. In this research, damage states are defined in terms of base-isolation system shear strain $(\%)$ and bridge pier displacement ductility $\left(\mu_{\mathrm{d}}\right)$. The experimental observations are considered to determine the damage states for the base-isolators resulting in pounding and unseating. Lead rubber bearing can take shear strain up to $400 \%$ before failure. Total deformation of bridge deck-girders and unseating issues in the whole bridge system are raised from such high strain. So this value is limited to $250 \%$ [12]. Limiting values for different damage 
states are taken from Hwang et al. [13] and Zhang and Huo [14]. Outline of distinctive damage states' physical appearance and criteria are displayed in Table 3.

\begin{tabular}{lllllll}
\hline $\begin{array}{l}\text { Damage } \\
\text { State }\end{array}$ & $\rightarrow$ & Slight & Moderate & Extensive & Collapse & Ref \\
\hline $\begin{array}{l}\text { Bridge } \\
\text { components }\end{array}$ & $\begin{array}{l}\text { Physical } \\
\text { phenomenon } \rightarrow\end{array}$ & $\begin{array}{l}\text { Cracking } \\
\text { and }\end{array}$ & $\begin{array}{l}\text { Moderate } \\
\text { cracking and } \\
\text { spalling }\end{array}$ & $\begin{array}{l}\text { Degradlation } \\
\text { spathout collapse }\end{array}$ & $\begin{array}{l}\text { Failure } \\
\text { leading to } \\
\text { collapse }\end{array}$ & FEMA [15] \\
Bridge pier & $\begin{array}{l}\text { Displacement } \\
\text { ductility } \mu_{\mathrm{d}}\end{array}$ & $\mu_{\mathrm{d}}>1.0$ & $\mu_{\mathrm{d}}>1.2$ & $\mu_{\mathrm{d}}>1.76$ & $\mu_{\mathrm{d}}>4.76$ & $\begin{array}{l}\text { Hwang et al } \\
\text { [13] }\end{array}$ \\
LRB & Shear strain $\gamma(\%)$ & $\gamma>100$ & $\gamma>150$ & $\gamma>200$ & $\gamma>250$ & $\begin{array}{l}\text { Zhang and } \\
\text { Huo [14] }\end{array}$ \\
\hline
\end{tabular}

Table 3: Damage states of bridge components.

\section{SEISMIC FRAGILITY ANALYSIS}

The fragility curve expresses the probability of damage corresponding to a given damage state at several levels of seismic events. In fact, the fragility curve describes the relation between the intensity measure and the level of possible seismic damage. In order to accurately develop fragility curves, it is important to choose an appropriate earthquake intensity measure for structure under study. Intensity measures that indicate the severity of the earthquake as appropriate for fragility analysis include Sa, PGA, PGV, and PGD. Fragility curves can be obtained from logical regression analysis of real or simulated damage information or numerical solution methods.

Fragility curves distribute the failure between slight, moderate, extensive, and collapse states according to HAZUS-MH [15]. These curves are plotted separately for each damage state for a set of ground motions and are used as input to the structural damage calculation.

Researchers have previously used various methods to obtain fragility curves [16]. Billah and Alam [16] have surveyed diverse methods and proposed a technique to obtaining a hybrid fragility curve. The research examined the preferences, shortcomings, and imperatives of all the strategies in assessing seismic vulnerability of bridges. The fragility function is a probabilistic method that portrays the probability of damaging a structure beyond a specific damage level for a certain ground motion intensity [17]. The fragility of a structure, is expressed as the conditional probability of a damage state (DS) occurring given a specific intensity measure (IM), which can be expressed mathematically as [18]:

$$
\text { Fragility }_{D S}(y)=P[D M \geq D S \mid I M=y]
$$

The relationship of the engineering demand parameter (EDP) and the IM is set up by a probabilistic seismic demand model (PSDM) in this research. By utilizing the incremental dynamic analysis (IDA) on the bridge system, the PSDM is formed. There are two methods to create the PSDM: the scaling approach $[10,14]$ and the cloud approach $[19,20,21,22]$. The cloud method is utilized in assessing the seismic fragility function of the bridge piers and lead rubber bearing systems in this study.

The shear strain (\%) of the LRB and pier displacement ductility are selected as the EDPs, and the spectral acceleration at the fundamental period of the bridge (Sa, T1) of each ground motion is taken as the IM. Regression analysis is performed to obtain the mean and standard deviation of each damage condition by assuming the power-law function [23] in the cloud method. The logarithmic relationship between IM and median EDP is expressed as follows. 


$$
E D P=a(I M)^{b} \text { or }, \ln (E D P)=\ln (a)+b \ln (I M)
$$

In this correlation, $a$ and $b$ are coefficients that can be estimated from a regression. The lognormal distribution is recommended for the EDPs by Gradoni et al. [24]. In order to obtain adequate data for the cloud approach, IDA is carried out rather than the nonlinear time history analysis. The ground motions are scaled from a very low IM to a high IM for the IDA. The time history analysis and scaling are repeated until dynamic instability in the shape of large drifts occurs, demonstrating structural collapse. This reduced the computational time and provided adequate damage data for generating fragility curves. Each intensity level of a specific ground motion can be considered as a one-time history analysis. Hence, it was possible to generate adequate damage data corresponding to a diverse ground motion intensity levels. The logarithmic standard deviation (dispersion) of the demand parameters, $\beta_{E D D P \mid I M}$ conditioned upon the IM is estimated using the following equation [25].

$$
\beta_{E D P \mid I M}=\sqrt{\frac{\sum_{i=1}^{N}\left(\ln (E D P)-\ln \left(a I M^{b}\right)\right)^{2}}{N-2}}
$$

In this equation, $N$ is the number of simulation cases.

Fragility curves are created utilizing the following equation from Padgett [26].

$$
P[D S \mid I M]=\varphi\left[\frac{\ln (I M)-\ln \left(I M_{n}\right)}{\beta_{\text {comp }}}\right]
$$

In this equation, $\Phi[$ ] is the standard normal cumulative distribution function and

$$
\ln \left(I M_{n}\right)=\frac{\ln \left(S_{c}\right)-\ln (a)}{b}
$$

$\mathrm{IM}_{\mathrm{n}}$ is characterized as the median value of the intensity measure for the chosen damage states. The following equation presents the dispersion [26].

$$
\beta_{\text {comp }}=\frac{\sqrt{\beta_{E D P \mid I M}^{2}+\beta_{c}^{2}}}{b}
$$

In this equation, $S_{c}$ and $\beta_{c}$ are the median and dispersion values for a specific damage state of the bridge components (bridge pier and isolation bearing), respectively. The coefficient of variation $(\mathrm{COV})$ is related to each damage state for related uncertainties. $\mathrm{COV}$ is assumed to be 0.25 for slight and moderate damage states and 0.5 for the extensive and collapse damage states [18]. The following equation is used to calculate the dispersion value [27].

$$
\beta_{c}=\sqrt{\ln \left(1+C O V^{2}\right)}
$$

The total bridge system fragility function is more conceivable than the individual component fragility function $[14,19,21,22]$. The global damage likelihood can be simply assessed utilizing the series system and first-order reliability theory. Moreover, the upper and lower bound of failure likelihood of the bridge can be determined utilizing Eq. (8). Both bounds present a conservative and un-conservative estimation of damage likelihoods, respectively.

$$
\max _{i=1}^{n}\left[P\left(F_{i}\right)\right] \leq P\left(F_{\text {system }}\right) \leq 1-\prod_{i=1}^{n}\left[1-P\left(F_{i}\right)\right]
$$


In this equation, $\mathrm{P}\left(\mathrm{F}_{\mathrm{i}}\right)$ represents the probability of exceeding the prescribed bound of the component's actual damage state. Moreover, $\mathrm{P}\left(\mathrm{F}_{\text {system }}\right)$ is for the whole bridge system.

\section{RESULTS}

Fragility functions are developed for the based-isolated curved bridge considering the fragilities of the pier and LRB for various modeling techniques. The fragility functions, assuming a lognormal distribution with respect to the median of seismic intensity ( $\mathrm{Sa}, \mathrm{T} 1$ ), are generated using Eq. (4), and calibrated with the damage states as shown in Table 3. To evaluate the effect of LRB modeling techniques on the relative fragility of each component, fragility curves are developed for the piers and isolation bearings at abutments and piers. However, the fragilities of the pier and abutment bearings are not provided here due to space limitations. Fig. 5 compares the fragility curves for the LRB at four damage states. Fig. 5 shows that the when LRB is modeled using KikuchiAikenLRB technique, independent of the considered damage level, LRB is less vulnerable during a seismic event. As the damage level changes from slight to collapse, the contrast between the relative vulnerability of KikuchiAikenLRB and other techniques increase and become more visible. This interpretation is also accurate for the LeadRubberX and ElastomericX techniques, but its value is less obvious.
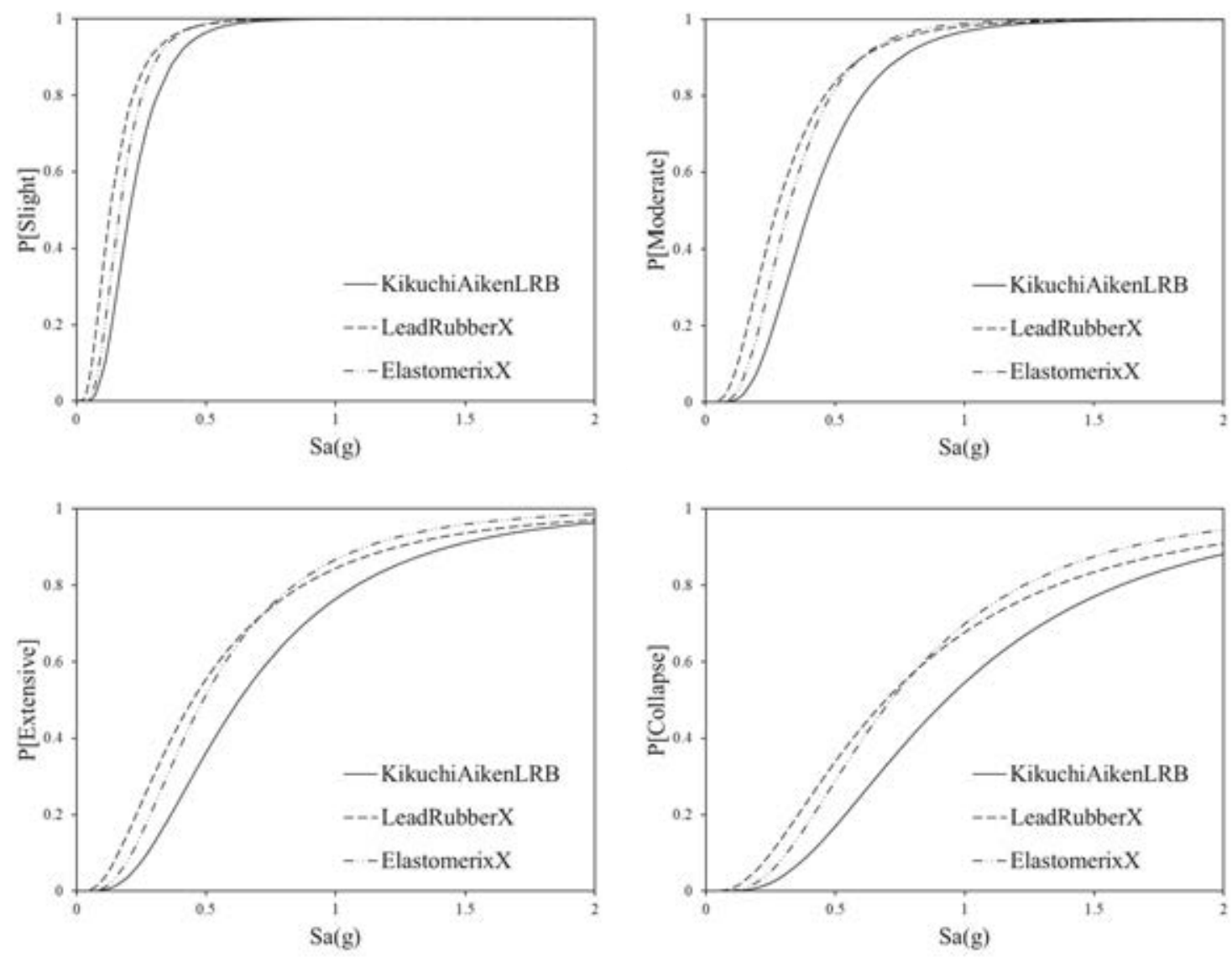

Figure 5: Comparison of fragility curves of LRB.

As the collapse of bridge components (column and/or bearing) will lead to the collapse of the bridge, the fragility curves of each component should be combined to get a system fragility curve. After obtaining the bridge component fragility curves, the bridge system fragility 
curves are determined according to Eq. (8). Fig. 6 shows the system fragility curves of the bridge with various modeling techniques. The same observation can be seen as a bearing isolation system for the bridge system, as utilizing KikuchiAikenLRB can lead to a reduced damage compared to the other techniques. The bridge fragility curves of Elastomeric $\mathrm{X}$ and LeadRubberX techniques are very similar. The bridge system fragility demonstrates that system fragility is generally influenced at the extensive and collapse damage level due to the using KikuchiAikenLRB techniques. It is also observed that the ElastomericX and LeadRubberX have almost identical fragility curves.
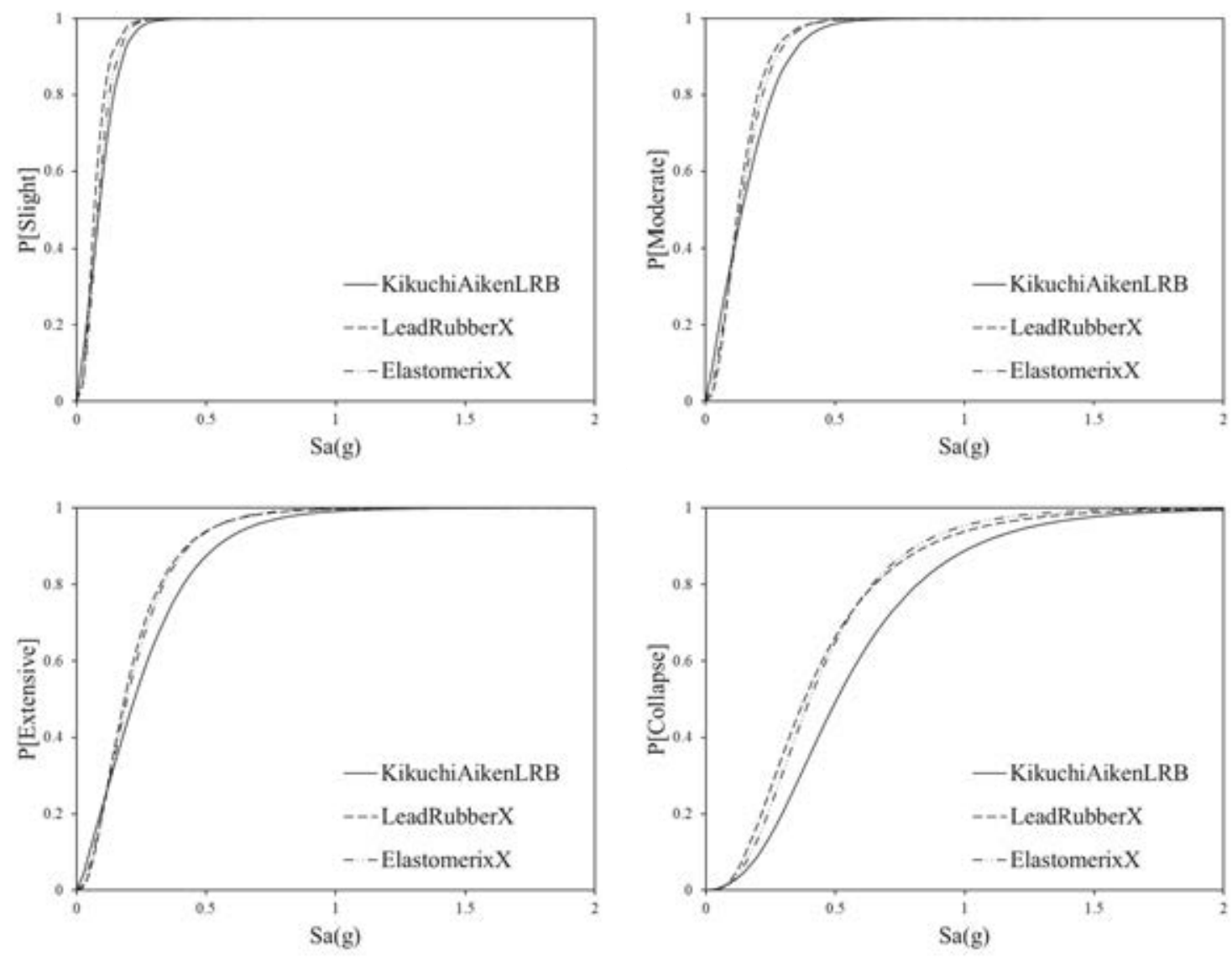

Figure 6: Comparison of fragility curves of Bridge System.

\section{CONCLUSIONS}

In this paper, various bearing isolation modeling techniques are assessed in terms of pier displacement and LRB deformation. Increment dynamic analysis is implemented to derive the appropriate data for fragility analysis. Then, seismic fragility curves are obtained for each bridge component as well as the bridge system. According to the results of the numerical analysis, the following conclusions are drawn:

- KikuchiAikenLRB is susceptible to lower shear force as compared to ElastomericX and LeadRubberX significantly.

- The influence of modeling techniques on the fragility of LRB shows increased susceptibility of exceeding different damage states in ElastomericX and LeadRubberX techniques compared to the KikuchiAikenLRB technique. 
- Extensive and collapse damage states of the bridge system fragility considering the KikuchiAikenLRB technique is mostly affected than the other two techniques.

- The likelihood of an isolated bridge exceeding collapse damage level is highly dependent on the adopted modeling techniques. The higher probability of the bridge experiencing collapse is mainly attributable to the fragility of the bearings arising from the LeadRubberX and ElastomericX LRB modeling techniques.

\section{Acknowledgment}

The Natural Sciences and Engineering Research Council (NSERC) of Canada supported this study through the Discovery Grant. The financial support is highly appreciated.

\section{REFERENCES}

[1] M. Kumar, A.S. Whittaker, M.C, Constantinou, An advanced numerical model of elastomeric seismic isolation bearings, Earthquake Engineering \& Structural Dynamics, 43(13), 1955-1974,2014.

[2] I. Buckle, S. Nagarajaiah, K. Ferrell, Stability of elastomeric isolation bearings: Experimental study, Journal of Structural Engineering, 128(1), 3-11, 2002.

[3] I.G. Buckle, J.M. Kelly, Properties of slender elastomeric isolation bearings during shake table studies of a large-scale model bridge deck, Special Publication, 94, 247-270, 1986.

[4] I. Buckle, H. Liu, Experimental determination of critical loads of elastomeric isolators at high shear strain, NCEER Bull, 8(3), 1-5, 1994.

[5] C.G. Koh, J.M. Kelly, Effects of axial load on elastomeric isolation bearings, Earthquake Engineering Research Center, University of California: Berkeley, United States, 1987.

[6] A. Elgamal, L. He, Vertical earthquake ground motion records: an overview, Journal of Earthquake Engineering, 8(05), 663-697, 2004.

[7] S. Shekhar, J. Ghosh, S. Ghosh, Influence of bearing types and design code advances on seismic vulnerability of simply supported highway bridges, Journal of Earthquake Engineering, 1-27, 2003.

[8] Monzon, E.V, Seismic Performance of Curved Steel Plate Girder Bridges with Seismic Isolation (Dissertation), Nevada: University of Nevada, Reno, 2013.

[9] PEER (Pacific Earthquake Engineering Research), new ground motion selection procedures and selected motions for the PEER transportation research program, PEER report 2011/03. Berkeley, CA: University of California, 2011.

[10] Alam MS, Bhuiyan AR, Billah AHMM, Seismic fragility assessment of SMA- bar restrained multi-span continuous highway bridge isolated with laminated rubber bearing in medium to strong seismic risk zones, Bulletin of Earthquake Engineering, 10, 18851909, 2012.

[11] Bhuiyan MAR, Alam MS, Seismic vulnerability assessment of a multi-span continuous highway bridge fitted with shape memory alloy bars and laminated rubber bearings, Earthquake Spectra, 28, 1379-1404, 2012. 
[12] JRA. Specifications for highway bridges-part V: Seismic design. Tokyo, Japan: Japan Road Association, 2002.

[13] Hwang H, Liu JB, Chiu YH, Seismic fragility analysis of highway bridges, MAEC RR4. Urbana: Mid America Earthquake Center, 2001.

[14] Zhang J, Huo Y, Evaluating effectiveness and optimum design of isolation devices for highway bridges using the fragility function method, Engineering Structures, 31, 16481660, 2009.

[15] Federal Emergency Management Agency (FEMA), HAZUS-MH software, Washington DC, 2003.

[16] Billah AHMM, Alam MS, Seismic fragility assessment of highway bridges: a state-of the- art review, Structure and Infrastructure Engineering, 11, 804-832, 2015.

[17] Billah AHMM, Alam MS, Seismic fragility assessment of concrete bridge pier reinforced with super-elastic shape memory alloy, Earthq. Spectra, 31, 1515-1541, 2014.

[18] Porter K, Kennedy R, Bachman R, Creating fragility functions for performance based earthquake engineering, Earthquake Spectra, 23(2), 471-489, 2007.

[19] Choi E, DesRoches R, Nielson BG, Seismic fragility of typical bridges in moderate seismic zones, Engineering Structures, 26, 187-199, 2004.

[20] Mackie KR, Stojadinović B, Fragility curves for reinforced concrete highway overpass bridges, 13th world conference on earthquake engineering, Vancouver, B.C., Canada, August 2004.

[21] Nielson BG, DesRoches R, Seismic fragility curves for typical highway bridge classes in the central and southeastern United States, Earthquake Spectra, 23, 615-633, 2007.

[22] Nielson BG, DesRoches R, Seismic fragility methodology for highway bridges using a component level approach, Earthq. Engr. and Structural Dynamics, 36, 823-839, 2007.

[23] Cornell AC, Jalayer F, Hamburger RO, Probabilistic basis for 2000 SAC federal emergency management agency steel moment frame guidelines, Journal of Engineering Structure, 128, 526-532, 2002.

[24] Gardoni P, Mosalam KM, Der Kiureghian A, Probabilistic seismic demand models and fragility estimates for RC bridges, of Earthquake Engineering, 7(1), 79-106, 2003.

[25] Baker JW, Cornell CA, Vector-valued ground motion intensity measures for probabilistic seismic demand analysis, Pacific earthquake engineering research report 2006/08. University of California Berkeley: PEER Centre, 2006.

[26] Padgett JE, Seismic vulnerability assessment of retrofitted bridges using probabilistic methods (Dissertation), Atlanta: Georgia Institute of Technology, 2007.

[27] Nielson BG, Analytical fragility curves for highway bridges in moderate seismic zones (Dissertation), Atlanta: Georgia Institute of Technology, 2005.

[28] Chang, G.A., and Mander, J.B., Seismic Energy Based Fatigue Damage Analysis of Bridge Columns: Part 1 - Evaluation of Seismic Capacity, NCEER Technical Report No. NCEER-94-0006 State University of New York, Buffalo, N.Y, 1994.

[29] Applied Technology Council, Quantification of building seismic performance factors. Redwood City, USA: FEMA; 2009:P695. 